\title{
Respiratory influence on left atrial volume calculation with 3D-echocardiography
}

Mathias Sørgaard ${ }^{1 *}$, Jesper J. Linde ${ }^{1}$, Hafsa Ismail², Niels Risum², Klaus F. Kofoed ${ }^{1,3}$, Jørgen T. Kühl', Benjamin Tittle², Walter B. Nielsen² and Jens D. Hove ${ }^{2,4}$

\begin{abstract}
Background: Left atrial volume (LAV) estimation with 3D echocardiography has been shown to be more accurate than 2D volume calculation. However, little is known about the possible effect of respiratory movements on the accuracy of the measurement.

Methods: 100 consecutive patients admitted with chest pain were examined with 3D echocardiography and LAV was quantified during inspiratory breath hold, expiratory breath hold and during free breathing.

Results: Of the 100 patients, only 65 had an echocardiographic window that allowed for 3D echocardiography in the entire respiratory cycle. Mean atrial end diastolic volume was $45.4 \pm 14.5$ during inspiratory breath hold, $46.4 \pm$ 14.8 during expiratory breath hold and $45.6 \pm 14.3$ during free respiration. Mean end systolic volume was $17.6 \pm 7.8$ during inspiratory breath hold, $18.8 \pm 8.0$ during expiratory breath hold and $18.3 \pm 8.0$ during free respiration. No significant differences were seen in any of the measured parameters.

Conclusions: The present study adds to the feasibility of 3D LAV quantitation. LAV estimation by 3D echocardiography may be performed during either end-expiratory or end-inspiratory breath-hold without any significant difference in the calculated volume. Also, the LAV estimation may be performed during free breathing.
\end{abstract}

Keywords: Three dimensional transthoracic echocardiography, Left atrial volume, Quantitation, Respiration

\section{Background}

Left atrial (LA) size and function has emerged as a clinically useful parameter in predicting atrial fibrillation $[1-3]$, risk of stroke $[4,5]$, heart failure [6, 7], and death $[4,8]$. Also, LA volume (LAV) is related to the severity of left ventricular diastolic dysfunction [9, 10]. Twodimensional (2D) echocardiography has been used to assess LAV $[11,12]$ but it has been shown to significantly underestimate the size of the LA compared to magnetic resonance imaging (MRI) and computer tomography (CT) $[13,14]$. Three dimensional (3D) echocardiography has evolved during the last decade, and the use of multidimensional phase-array detectors have allowed for real time 3D-echocardiography to be performed in a clinical setting. A major advantage of this technique is the independency of geometric assumptions. A number of

\footnotetext{
* Correspondence: mathiassoergaard@hotmail.com

'Department of Cardiology, The Heart Centre, Rigshospitalet, University of

Copenhagen, Blegdamsvej 9, 2100-CPH København, Denmark

Full list of author information is available at the end of the article
}

studies have demonstrated the feasibility of 3D echocardiography for the assessment of LAV, and it has been validated against magnetic resonance imaging (MRI) [15-17], and multidetector computed tomography (MDCT) $[18,19]$.

Image quality is crucial for accurate diagnosis and quantitation. Conventional image acquisition for LAV assessment is performed during breath hold [20]. In some patients a better echo window may be present at end-inspiration, while other patients with pulmonary disease may have difficulties in cooperating.

Studies suggest that respiratory variations may affect the LAV. Several studies have shown a decrease in the left atrial size in healthy volunteers following increased intrathoracic pressure [21-23]. However, it is unknown whether normal respiratory variation interfere with LAV measurement and whether this should be accounted for during image acquisition. Accordingly, the current study was designed to study the possible influence of respiratory variations on 3D echocardiographic assessment of 
LAV and function and examine the influence of free breathing.

\section{Methods \\ Study patients}

Patients for this study were derived from the cohort of patients included in the $\mathrm{CATCH}$ trial (CArdiac $\mathrm{CT}$ in the treatment of acute CHest pain) [24]. With approval from the institutional review board and the local ethics committee, we prospectively enrolled 100 patients with suspected coronary artery disease and performed 3D transthoracic echocardiography for evaluation of cardiac function. Informed consent was obtained from all enrolled patients. The study was performed in accordance with the declaration of Helsinki.

\section{Echocardiographic data acquisition and LAV by Real-Time 3D echocardiography}

Transthoracic echocardiography was performed by an experienced cardiologist (TTE and TEE certified by the European Society of Cardiology) with patients in the left lateral decubitus position using a commercially available echocardiographic system (iE33; Philips Medical Systems, Andover, MA). All echocardiographic images were stored digitally, and measurements were performed offline using the commercially available QLAB software package (Philips Medical Systems). Measurements were obtained for three consecutive beats and averaged for all calculations. LAV was indexed to body surface area. Image quality was visually divided into 5 groups, according to the following classification. $5=$ optimal image quality, $4=$ slightly reduced image quality, without implications on interpretation, 3 = reduced image quality with few interpretation difficulties, $2=$ reduced image quality with extensive interpretation difficulties, $1=$ poor image quality with severe implications on interpretation or non-diagnostic image quality.

LAV by real-time 3D echocardiography was collected in full-volume mode during inspiratory breath hold, expiratory breath hold and free breathing, by instruction from the operator, using an $\times 3-1$ matrix-array transducer. The correct breath holding was verified by visual inspection before the subsequent data acquisition. Acquisition was triggered to the electrocardiographic $\mathrm{R}$ wave. Care was taken to ensure that the entire LA was included within a pyramidal 3D data set. Image acquisition was further optimized to ensure the highest possible frame rate (adjustment of sector width and depth). LAV by $3 \mathrm{D}$ echocardiography was derived from semiautomatic tracing of the LA endocardium, at ventricular end-systole in the apical 4- and 2 chamber planes, using Philips QLAB software. This was performed by marking 5 points in the atrial surfaces of the mitral annulus: at the anterior, inferior, lateral, and septal annuli, and the fifth point at the apex of the left atrium. Once this was complete, the endocardial surface was automatically delineated, and a mathematical model of the left atrium could be visualized from different points of views, and the LAV calculation was obtained (Fig. 1). Manual modification was made to correct the automatic tracings when necessary. At the valve leaflets the tracing was limited to the annular plane.

We measured the LAV, at end atrial diastole and systole. Atrial diastole and systole was determined during the analyses by visual inspections of the time points for mitral valve opening and closing. From these volumes the LA ejection fraction and LA stroke volume were calculated. The volumes were quantified during inspiratory breath hold, expiratory breath hold and during free breathing. All the inspiratory images were analyzed first, then the expiratory images, and in the end the images during free breathing. This was to ensure, that previous results from the same patient, would not be memorable for the person doing the analyses.

Inter- and intra-observatory analyses were made on 20 randomly selected studies, at free breathing, to make sure that results were reproducible.

\section{Statistical analysis}

Statistical analyses were performed using SAS version 9.2. Continuous variables were described as means $\pm S D$ and compared with paired $t$ tests. Bland-Altman plots were used to compare the different methods and were constructed using GraphPad Prism 6, CA 92037, USA.

\section{Results}

Patient characteristics are shown in Table 1. 100 patients were included but 35 had insufficient echo windows that did not allow for 3D echocardiography independently of respiration (18 due to poor overall image quality in 17 patients a satisfactory echo window was not obtainable at both inspiratory and expiratory breath-hold). No significant difference was seen in the characteristics

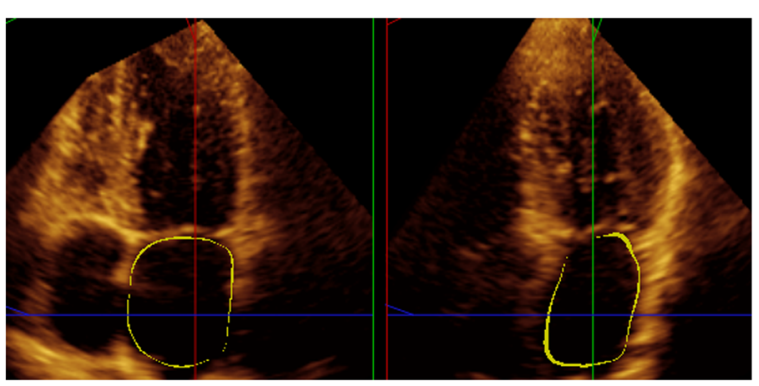

Fig. 1 The QLAB echo image from the analysis of a patient is shown. The image illustrates the border delineation during atrial diastole. LAV was measured from endocardial tracing. At the valve leaflets the tracing was limited to the annular plane 
Table 1 Study population demographics

\begin{tabular}{|c|c|}
\hline Patients (N) & 65 \\
\hline Male gender-no. (\%): & $43(66)$ \\
\hline \multicolumn{2}{|l|}{ Age-years } \\
\hline Mean & 52.9 \\
\hline Range & $22-82$ \\
\hline \multicolumn{2}{|l|}{$B M I$} \\
\hline Mean & 26.3 \\
\hline Range & $18-37$ \\
\hline \multicolumn{2}{|l|}{ Coronary artery disease Risk factors-no (\%) } \\
\hline Hypertension & $23(35.4)$ \\
\hline Hypercholesterolemia & $24(36.9)$ \\
\hline Family history of $C A D$ & $14(21.5)$ \\
\hline Diabetes Mellitus & $4(6.2)$ \\
\hline \multicolumn{2}{|l|}{ Tobacco use } \\
\hline Current smokers & $25(38.5)$ \\
\hline Ever smokers & $43(66.2)$ \\
\hline Pack years mean & 21.9 \\
\hline Previous myocardial infarction & $9(13.8)$ \\
\hline Known ischemic heart disease & $11(16.9)$ \\
\hline Previous apoplexies/TCI (\%) & $4(6.2)$ \\
\hline Pheripheral vascular disease (\%) & $1(1.5)$ \\
\hline LVEF (range) & $58.8(25-60)$ \\
\hline
\end{tabular}

$B M I$ body mass index, $C A D$ coronary artery disease, $T C l$ transitory cerebral ischemia

between the patients that were included and those that were excluded.

The studies had an average quality of 3.5 , so quality above 3.5 was classified as high, and quality below 3.5 were classified as low. Using this classification, 40 patients had high quality images, and 25 had low quality images. The mean frame rate was $16 \pm 5$ frames/sec.

The LA size was normal in 58 patients, mildly dilated in 2 patients, moderately dilated in 3 patients and severely dilated in 2 patients according to normal reference values of the size of the left atrium [25].

\section{End diastolic atrial volume}

Mean end diastolic atrial volume (EDV) was $45.4 \mathrm{~mL} \pm$ $14.5 \mathrm{~mL}$ during inspiratory breath hold, $46.4 \mathrm{~mL} \pm 14.8 \mathrm{~mL}$ during expiratory breath hold and $45.6 \mathrm{~mL} \pm 14.3 \mathrm{~mL}$ during normal respiration (Fig. 2).

\section{End systolic atrial volume}

Mean end systolic atrial volume (ESV) was $17.6 \mathrm{~mL} \pm$ $7.8 \mathrm{~mL}$ during inspiratory breath hold, $18.8 \mathrm{~mL} \pm 8.0 \mathrm{~mL}$ during expiratory breath hold and $18.3 \mathrm{~mL} \pm 8.0 \mathrm{~mL}$ during normal respiration (Fig. 2). (inspiratory vs. expiratory, $p=0.11$; inspiratory vs. normal, $p=0.21$; expiratory vs. normal, $p=0.63$ ).

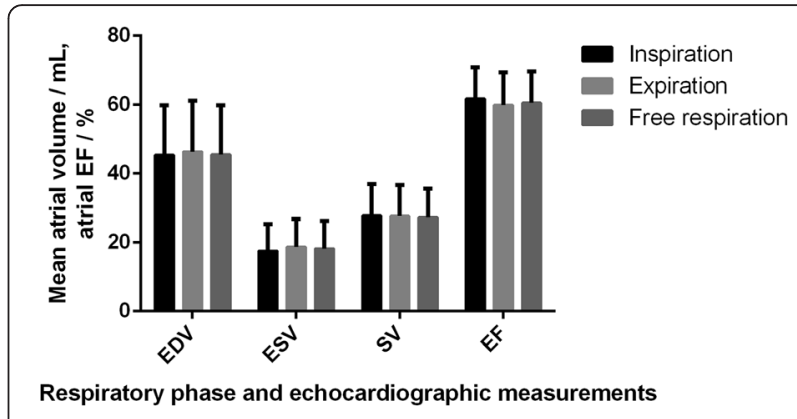

Fig. 2 Mean end diastolic volume, end systolic volume, stroke volume and ejection fraction of the left atrium, during the different respiratory phases. Volumes are shown as $\mathrm{mL}$ 's and EF as \%. Vertical lines are showing the standard deviations. No significant differences were found. EDV = end diastolic atrial volume, ESV = end systolic atrial volume, $\mathrm{SV}=$ atrial stroke volume, $\mathrm{EF}=$ atrial ejection fraction

\section{Atrial stroke volume}

Mean atrial stroke volume (SV) was $27.8 \mathrm{~mL} \pm 9.1 \mathrm{~mL}$ during inspiratory breath hold, $27.6 \mathrm{~mL} \pm 9.0 \mathrm{~mL}$ during expiratory breath hold and $27.3 \mathrm{~mL} \pm 8.3 \mathrm{~mL}$ during normal respiration (Fig. 2) (inspiratory vs. expiratory, $p=0.86$; inspiratory vs. normal, $p=0.62$; expiratory vs. normal, $p=0.74)$.

\section{Atrial ejection fraction}

Mean atrial ejection fraction (EF) was $61.8 \% \pm 9.1 \%$ during inspiratory breath hold, $60.0 \% \pm 9.3 \%$ during expiratory breath hold and $60.6 \% \pm 9.0 \%$ during normal respiration (Fig. 2) (inspiratory vs. expiratory, $p=0.23$; inspiratory vs. normal, $p=0.37$; expiratory vs. normal, $p=0.63$ ).

There was no significant intra - or interobserver differences between any of the measured parameters (Fig. 3).

There were no respiratory differences at neither high nor low atrial volumes. This is shown by Bland-Altman plots (Fig. 4a and b), where points are distributed equally around the mean, at high, low and intermediate volumes. Further statistical results on the differences of the various measurements and respiratory phases are shown in Table 2. Furthermore, when dividing the population with regard to image quality, no significant interobserver or intraobserver differences were seen between the measured parameters in the low-quality group versus in the high-quality group.

\section{Discussion}

LAV provides information on the severity of left ventricular diastolic dysfunction, and has also been shown to carry important prognostic information. In addition, LAV by echocardiography and MDCT has been shown to be a predictor of death in patients with acute myocardial infarction [26, 27]. Hence, LAV is an important measurement in a large subset of patients with heart 


\section{a} End diastolic volume, intraobservatory differences

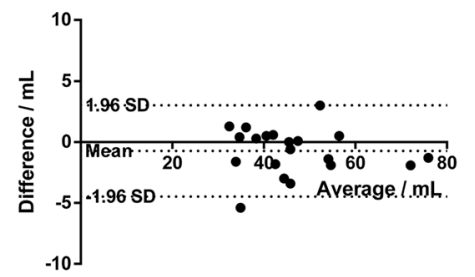

End systolic volumes, intraobserver differences

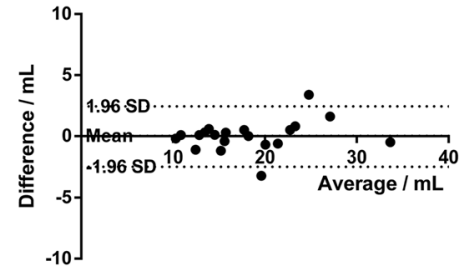

b

End diastolic volume, interobservatory differences

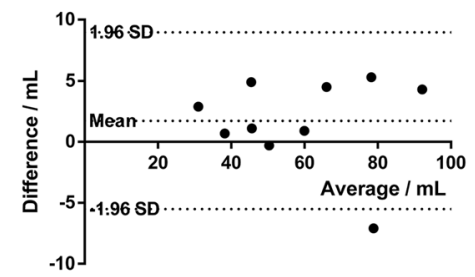

End systolic volumes, interobserver differences

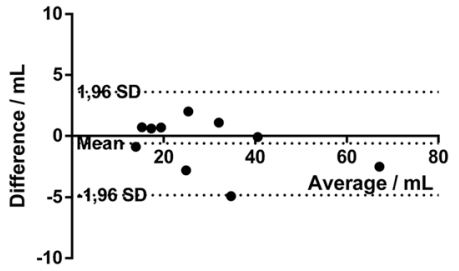

Fig. 3 a Bland-Altman plot of the intraobserver end diastolic and systolic atrial volume measurements during free breathing, showing a small intraobserver difference. $\mathbf{b}$ Bland-Altman plot of the interobserver end diastolic and systolic atrial volume measurements during free breathing, showing a small interobserver difference

a End diastolic volume, inspiratory - expiratory

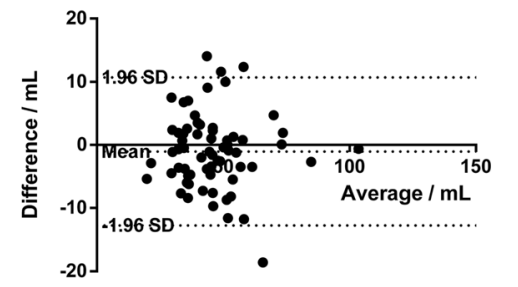

End diastolic volume, inspiratory - free breathing

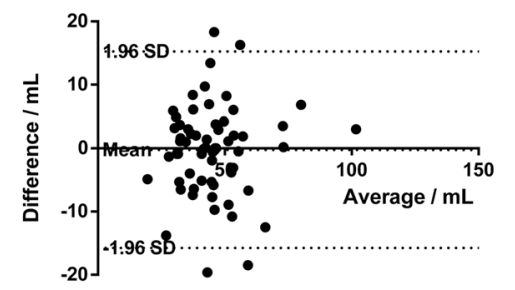

End diastolic volume, expiratory - free breathing

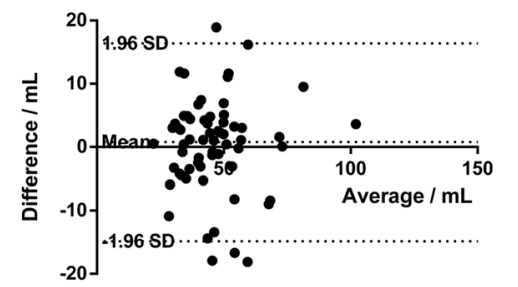

b

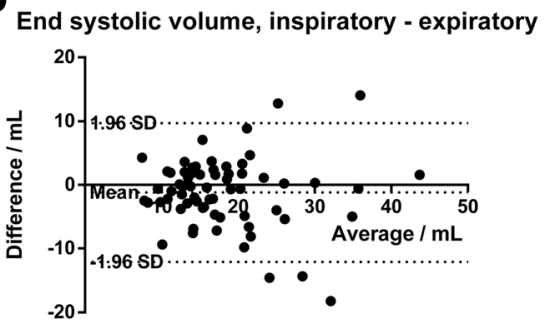

End systolic volume, inspiratory - free breathing

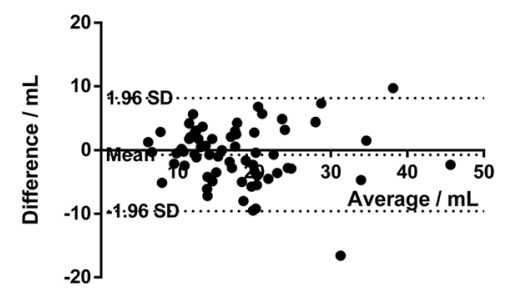

End systolic volume, expiratory - free breathing

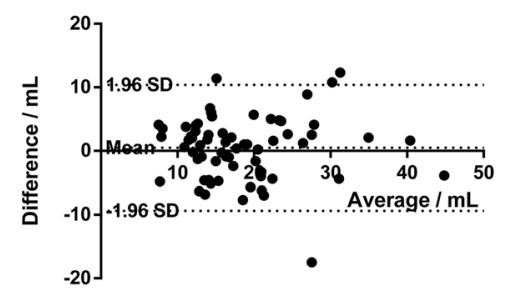

Fig. 4 a Bland-Altman plot for end diastolic volumes showing differences between the measurements at the various breathing phases (Inspiratory vs. expiratory: bias $=1.0 \mathrm{~mL} \pm 6.0 \mathrm{~mL}$, inspiratory vs. free breathing: bias $=-0.3 \mathrm{~mL} \pm 7.9 \mathrm{~mL}$ and expiratory vs. free breathing: bias $=0.8 \mathrm{~mL} \pm 8.0 \mathrm{~mL}$ ). b Bland-Altman plot for end systolic volumes showing differences between the measurements at the various breathing phases (Inspiratory vs. expiratory: bias $=-1.2 \mathrm{~mL} \pm 5.6 \mathrm{~mL}$, inspiratory vs. free breathing: bias $=-0.7 \mathrm{~mL} \pm 4.5 \mathrm{~mL}$ and expiratory vs. free breathing: bias $=0.5 \mathrm{~mL} \pm 5.0 \mathrm{~mL}$ ) 
Table 2 Statistics on the differences between the various measurements and respiratory states

\begin{tabular}{|c|c|c|c|c|c|}
\hline & & Mean bias $\pm \mathrm{SD}$ & Correlation coefficiency & $95 \%$ limits of agreement & Coefficient of variation \\
\hline \multirow[t]{3}{*}{$\overline{\mathrm{EDV}}$} & Inspiratory vs. expiratory & $-1.0 \pm 6.0$ & $-0.043(p=0.73)$ & $-12.79-10.71$ & $9.3 \%$ \\
\hline & Inspiratory vs. free breathing & $-0.26 \pm 7.9$ & $0.038(p=0.77)$ & $-15.75-15.24$ & $12.2 \%$ \\
\hline & Expiratory vs. free breathing & $0.78 \pm 8.0$ & $0.071(p=0.58)$ & $-14.83-16.40$ & $12.2 \%$ \\
\hline \multirow[t]{3}{*}{ ESV } & Inspiratory vs. expiratory & $-1.19 \pm 5.6$ & $-0.048(p=0.71)$ & $-12.11-9.72$ & $19.1 \%$ \\
\hline & Inspiratory vs. free breathing & $-0.70 \pm 4.5$ & $-0.04(p=0.72)$ & $-9.57-8.16$ & $15.9 \%$ \\
\hline & Expiratory vs. free breathing & $0.49 \pm 5.0$ & $0.011(p=0.93)$ & $-9.39-10.37$ & $17.4 \%$ \\
\hline \multirow[t]{3}{*}{ SV } & Inspiratory vs. expiratory & $0.16 \pm 7.2$ & $0.011(p=0.93)$ & $-13.91-14.23$ & $18.2 \%$ \\
\hline & Inspiratory vs. free breathing & $0.48 \pm 7.8$ & $0.12(p=0.33)$ & $-14.86-15.82$ & $20.0 \%$ \\
\hline & Expiratory vs. free breathing & $0.31 \pm 7.5$ & $0.12(p=0.36)$ & $-14.38-15.01$ & $19.2 \%$ \\
\hline \multirow[t]{3}{*}{ EF } & Inspiratory vs. expiratory & $1.77 \pm 11.8$ & $-0.027(p=0.83)$ & $-21.41-24.95$ & $13.8 \%$ \\
\hline & Inspiratory vs. free breathing & $1.13 \pm 10.0$ & $0.013(p=0.92)$ & $-18.53-20.78$ & 11.6 \\
\hline & Expiratory vs. free breathing & $-0.64 \pm 10.8$ & $0.040(p=0.75)$ & $-21.80-20.52$ & $12.6 \%$ \\
\hline
\end{tabular}

$E F$ atrial ejection fraction, EDV end diastolic atrial volume, ESV end systolic atrial volume, SD standard deviation, $S V$ atrial stroke volume

disease, and hence it is important that the 3D image acquisition is as convenient as possible.

The present study investigates for the first time the influence of respiration on the LAV assessment by 3D echocardiography. The study shows that the LA quantitative parameters are not significantly affected by respiration. Thus LAV can be acquired accurately from image acquisition during end-expiration, end-inspiration or free breathing.

In this population 35 patients out of 100 were excluded because the image quality was insufficient for measuring the LAV by 3D echocardiography in all respiratory states. Our results show that the LAV may be measured in any respiratory state, and since only 18 patients were excluded because of poor overall image quality, the amount of patients in whom 3D echocardiographic measurement of the LAV is not possible may be reduced significantly, by selecting the respiratory state with the best view of the LA.

Early studies of LAV during mechanical ventilation indicated, that positive end-expiratory pressure might influence the LAV. Leithner et al. showed a progressive decrease in the LA size, in healthy volunteers when the PEEP pressure increased from 7 to $15 \mathrm{~cm}$ water using cardiac MR [23]. The volumes decreased in relation to simultaneous increase in lung volumes, and it was hypothesized that the reduced cardiac volumes were caused by cardiac compression related to the lung expansion. The volume decline during PEEP ventilation is supported by Riddervold et al., who showed a volume decline using sonomicrometry in an open and close chest dog experiment [21]. Presumably, lung expansion during end-inspiration did not reach the same extent, in this study. Also, the lung volume expansion in our study is more physiologic and may be associated with potential counteracting effects. Thus, during inspiration the right heart volume increases (due to negative intra thoracic pressure), whereas it decreases during PEEP pressure.

\section{Limitations}

Most of the patients had normal ejection fraction and a structurally normal heart. Cardiac diseases affecting the ejection fraction (constrictive pericarditis), or causing increased sensibility to intrathoracic pressure changes during respiration, are not accounted for in this study. Furthermore, we did not examine any patients suffering from serious respiratory distress. Other studies are necessary to explore these topics. Our patients, however, are representative of cardiac patients with a fairly high body-mass index affecting image quality. Image quality per se, however, did not seem to have any effect on the LAV quantification in either respiration cycle.

\section{Conclusion}

Our study indicates that differences in LAV related to respiration are negligible during normal breathing. In addition, we find that free breathing does not have influence on the LAV quantification.

\section{Competing interests}

Mathias Sørgaard, Jesper J. Linde and Klaus F. Kofoed all report that they have received lecturing fees from Toshiba Medical Systems, Japan. All other authors report no competing interests.

\section{Authors' contributions}

MS and JDH have contributed to all aspects of this work. JJL, NR, KFK, JTK and WBN have all contributed with the study design and critical revisions of the article. $\mathrm{HI}$ and BT have both contributed with data collection and critical revision of the article. All authors have approved the final submitted version of the article.

\section{Financial support}

This work was supported by grants from the Toyota foundation, The Danish Heart Foundation, and the Lundbeck foundation. 


\section{Author details}

'Department of Cardiology, The Heart Centre, Rigshospitalet, University of Copenhagen, Blegdamsvej 9, 2100-CPH København, Denmark. ²Department of Cardiology, Hvidovre Hospital, University of Copenhagen, København, Denmark. ${ }^{3}$ Department of Radiology, Rigshospitalet, University of Copenhagen, København, Denmark. ${ }^{4}$ Centre for Functional and Diagnostic Imaging and Research, Hvidovre Hospital, University of Copenhagen, København, Denmark

Received: 20 November 2015 Accepted: 3 March 2016

Published online: 12 March 2016

\section{References}

1. Psaty BM, Manolio TA, Kuller LH, Kronmal RA, Cushman M, Fried LP, et al. Incidence of and risk factors for atrial fibrillation in older adults. Circulation. 1997;96(7):2455-61.

2. Tsang TS, Barnes ME, Bailey KR, Leibson CL, Montgomery SC, Takemoto Y, et al. Left atrial volume: important risk marker of incident atrial fibrillation in 1655 older men and women. Mayo Clin Proc. 2001;76(5):467-75.

3. Vaziri SM, Larson MG, Benjamin EJ, Levy D. Echocardiographic predictors of nonrheumatic atrial fibrillation. The Framingham Heart Study. Circulation. 1994:89(2):724-30

4. Benjamin EJ, D'Agostino RB, Belanger AJ, Wolf PA, Levy D. Left atrial size and the risk of stroke and death. The Framingham Heart Study. Circulation. 1995;92(4):835-41.

5. Barnes ME, Miyasaka Y, Seward JB, Gersh BJ, Rosales AG, Bailey KR, et al. Left atrial volume in the prediction of first ischemic stroke in an elderly cohort without atrial fibrillation. Mayo Clin Proc. 2004;79(8):1008-14.

6. Gottdiener JS, Kitzman DW, Aurigemma GP, Arnold AM, Manolio TA. Left atrial volume, geometry, and function in systolic and diastolic heart failure of persons $>$ or $=65$ years of age (the cardiovascular health study). Am J Cardiol. 2006;97(1):83-9.

7. Takemoto Y, Barnes ME, Seward JB, Lester SJ, Appleton CA, Gersh BJ, et al. Usefulness of left atrial volume in predicting first congestive heart failure in patients $>$ or $=65$ years of age with well-preserved left ventricular systolic function. Am J Cardiol. 2005;96(6):832-6.

8. Gardin JM, McClelland R, Kitzman D, Lima JA, Bommer W, Klopfenstein HS, et al. M-mode echocardiographic predictors of six- to seven-year incidence of coronary heart disease, stroke, congestive heart failure, and mortality in an elderly cohort (the Cardiovascular Health Study). Am J Cardiol. 2001; 87(9):1051-7.

9. Pritchett AM, Mahoney DW, Jacobsen SJ, Rodeheffer RJ, Karon BL, Redfield MM. Diastolic dysfunction and left atrial volume: a population-based study. J Am Coll Cardiol. 2005:45(1):87-92.

10. Tsang TS, Barnes ME, Gersh BJ, Bailey KR, Seward JB. Left atrial volume as a morphophysiologic expression of left ventricular diastolic dysfunction and relation to cardiovascular risk burden. Am J Cardiol. 2002;90(12):1284-9.

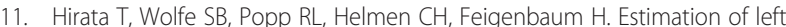
atrial size using ultrasound. Am Heart J. 1969;78(1):43-52.

12. Sahn DJ, DeMaria A, Kisslo J, Weyman A. Recommendations regarding quantitation in M-mode echocardiography: results of a survey of echocardiographic measurements. Circulation. 1978;58(6):1072-83.

13. Kuhl JT, Lonborg J, Fuchs A, Andersen MJ, Vejlstrup N, Kelbaek H, et al. Assessment of left atrial volume and function: a comparative study between echocardiography, magnetic resonance imaging and multi slice computed tomography. Int J Cardiovasc Imaging. 2012;28(5):1061-71. doi:10.1007/ s10554-011-9930-2

14. Kircher B, Abbott JA, Pau S, Gould RG, Himelman RB, Higgins CB, et al. Left atrial volume determination by biplane two-dimensional echocardiography: validation by cine computed tomography. Am Heart J. 1991;121(3 Pt 1): 864-71.

15. Rodevan O, Bjornerheim R, Ljosland M, Maehle J, Smith HJ, Ihlen H. Left atrial volumes assessed by three- and two-dimensional echocardiography compared to MRI estimates. Int J Card Imaging. 1999;15(5):397-410.

16. Keller AM, Gopal AS, King DL. Left and right atrial volume by freehand three-dimensional echocardiography: in vivo validation using magnetic resonance imaging. Eur J Echocardiogr. 2000;1:55-65.

17. Bauer F, Shiota T, Qin JX, White RD, Thomas JD. Measurement of left atrial and ventricular volumes in real-time 3D echocardiography. Validation by nuclear magnetic resonance. Arch Mal Coeur Vaiss. 2001;94(1):31-8.
18. Mahabadi AA, Samy B, Seneviratne SK, Toepker MH, Bamberg F, Hoffmann U, et al. Quantitative assessment of left atrial volume by electrocardiographicgated contrast-enhanced multidetector computed tomography. J Cardiovasc Comput Tomogr. 2009;3(2):80-7. doi:10.1016/j.jcct.2009.02.002S19345925(09)00078-1.

19. Miyasaka Y, Tsujimoto S, Maeba H, Yuasa F, Takehana K, Dote K, et al. Left atrial volume by real-time three-dimensional echocardiography: validation by 64-slice multidetector computed tomography. J Am Soc Echocardiogr. 2011;24(6):680-6. doi:10.1016/j.echo.2011.03.009.

20. Buck T, Franke A, Monaghan MJ. Three-dimensional Echocardiography. 2011.

21. Riddervold F, Smiseth OA, Risoe C. The effect of positive end-expiratory pressure ventilation on atrial filling. Acta Anaesthesiol Scand. 1991:35(5):448-52

22. Thomas L, Levett K, Boyd A, Leung DY, Schiller NB, Ross DL. Compensatory changes in atrial volumes with normal aging: is atrial enlargement inevitable? J Am Coll Cardiol. 2002;40(9):1630-5.

23. Leithner C, Podolsky A, Globits S, Frank H, Neuhold A, Pidlich J, et al. Magnetic resonance imaging of the heart during positive end-expiratory pressure ventilation in normal subjects. Crit Care Med. 1994:22(3):426-32.

24. Linde JJ, Kofoed KF, Sorgaard M, Kelbaek H, Jensen GB, Nielsen WB, et al. Cardiac computed tomography guided treatment strategy in patients with recent acute-onset chest pain: results from the randomised, controlled trial: CArdiac cT in the treatment of acute $\mathrm{CHest}$ pain (CATCH). Int J Cardiol. 2013;168(6):5257-62. doi:10.1016/j.ijcard.2013.08.020.

25. Vasan RS, Larson MG, Levy D, Evans JC, Benjamin EJ. Distribution and categorization of echocardiographic measurements in relation to reference limits: the Framingham Heart Study: formulation of a height- and sexspecific classification and its prospective validation. Circulation. 1997;96(6):1863-73.

26. Kuhl JT, Moller JE, Kristensen TS, Kelbaek H, Kofoed KF. Left atrial function and mortality in patients with NSTEMI an MDCT study. JACC Cardiovasc Imaging. 2011;4(10):1080-7. doi:10.1016/j.jcmg.2011.08.008.

27. Moller JE, Hillis GS, Oh JK, Seward JB, Reeder GS, Wright RS, et al. Left atria volume: a powerful predictor of survival after acute myocardial infarction. Circulation. 2003:107(17):2207-12. doi:10.1161/01.CIR.0000066318.21784.43.

\section{Submit your next manuscript to BioMed Central and we will help you at every step:}

- We accept pre-submission inquiries

- Our selector tool helps you to find the most relevant journal

- We provide round the clock customer support

- Convenient online submission

- Thorough peer review

- Inclusion in PubMed and all major indexing services

- Maximum visibility for your research

Submit your manuscript at www.biomedcentral.com/submit
C) BioMed Central 